\title{
AVALIAÇÃO “IN VITRO” DA ATIVIDADE ANTIMICROBIANA DA BENZIDAMINA
}

\section{THE EVALUATION OF THE ANTIMICROBIAL “IN VITRO” ACTIVITY OF BENZYDAMINE}

\author{
Ricardo Carvalho Vieira ${ }^{1}$ \\ Ivan de Oliveira Pereira ${ }^{2}$ \\ Jorge Kleber Chavasco ${ }^{3}$
}

\author{
${ }^{1}$ Mestre em Farmacologia-Cirurgião Dentista \\ ${ }^{2}$ Mestre e Professor da UNINCOR \\ ${ }^{3}$ Doutor, Professor Associado de Microbiologia da UNIFAL-MG ( Universidade Federal de Alfenas ) Alfenas - MG- \\ Brasil
}

\author{
Autor Correspondente \\ Prof. Dr. Jorge Kleber Chavasco \\ Universidade federal de Alfenas (UNIFAL-MG) \\ Rua Gabriel Monteiro da Silva 700 \\ 37130-000-Alfenas-MG-Brasil \\ Email: jkchavasco@uol.com.br
}

RESUMO: Com o objetivo de avaliar a provável atividade antibacteriana e antifúngica da benzidamina, determinou-se a Concentração Inibitória Mínima e a Concentração Bactericida/Fungicida Mínima, sobre várias amostras de microrganismos. Foram usadas as técnicas de difusão no agar (técnica do poço) e a da diluição em tubo. A avaliação da sensibilidade dos microrganismos à benzidamina, na técnica do poço, foi feita pela leitura dos halos de inibição e na técnica de diluição em tubo, pela inibição do crescimento. Os resultados mostraram que a benzidamina possui atividade antimicrobiana sobre as amostras de leveduras e bactérias testadas. Comparando as duas técnicas verificou-se que pela técnica de difusão em agar, o valor da concentração inibitória mínima (CIM) foi maior do que pela técnica de diluição em tubo.

Palavras chave: Benzidamina. ação antimicrobiana. concentração inibitória mínima. difusão em agar. Concentração Bactericida/Fungicida Mínima

\begin{abstract}
This paper aims the evaluation of the possible antibacterial an antifungical activity of benzydamine.Minimum inhibitory Concentration and Minimum Bactericide/Fungicide concentration in several microorganism samples were determined. Agar Difusion (tecnic of well)and tube dilution were the techniques used. Evaluation of microorganisms sensibility to benzydamine, was made through the reading of the inhibition halos in the agar difusion and growth inhibition $\mathrm{n}$ the tube dilution technique. The results showed that benzydamine has an antimicrobial activity in the yeast samples and in the tested bacteria. The comparison of the two techniques showed that in agar difusion technique the minimum inhibitory concentration value (MIC) was higher than in the tube dilution one.
\end{abstract}

Key words: benzydamine, antimicrobial action. Minimum inhibitory Concentration. Minimum Bactericide/Fungicide concentration. agar difusion. 


\section{INTRODUÇÃO}

Palazzo, em 1966, sintetizou a benzidamina (The Merck Index,1983), que chegou prometendo suprir a falta de um fármaco, com atividade analgésica e antiinflamatória, sem apresentar os efeitos nocivos ao trato gastrointestinal e nem provocar discrasias sangüíneas comuns aos antiinflamatórios não esteróides (AINES) já existentes, além dos efeitos imunodepressores e as contra- indicações existentes com o uso dos corticosteróides.

A benzidamina é usada como analgésico, antiinflamatório na medicina interna, ginecologia, cirurgia, pediatria, urologia, pneumologia e odontologia. Ł̀ comercializada na forma de drágeas, géis, gotas e solução (Korolkovas, 1982). É encontrada no comercio com os nomes comerciais como $\quad$ Flogoral ${ }^{\circledR}$, Benflogin $\AA$, Benzitrat $\AA, \quad$ Flogorosa ${ }^{\circledR}$ Ciflogex ${ }^{\circledR}$ entre outros ( DEF,2002).

De Gregório (1964), em ensaio duplo cego em vários modelos experimentais e diferentes condições patológicas, ou seja, em processos inflamatórios, afirmou que a benzidamina exerceu um considerável efeito analgésico, antiinflamatório e antipirético nos testes realizados.

A eficácia da benzidamina em pacientes submetidos à intervenções cirúrgicas da cavidade orofaríngea, foi constatada por Marchiori (1972), que observou uma diminuição no tempo de cicatrização das feridas cirúrgicas e seu valor na associação com antibióticos, pela ausência de efeitos colaterais e pela boa tolerância.

Balércia (1976) comprovou a ação antiinflamatória da benzidamina, em forma de creme dental, em pacientes portadores de gengivite, periodontites, estomatites e abcessos dentários.

Whiteside (1982) tratou pacientes que apresentavam possíveis faringites virais, com benzidamina e placebo, em soluções colutórias. Os resultados favoráveis da ação da benzidamina foram clinicamente evidentes. Kim et al, (1986) recomendou a benzidamina para tratamento da mucosite causada por radiação.

Ganança et al. (1988), em estudo comparativo entre a benzidamina e Hexomedine ${ }^{\circledR}$, associados a tetracaína em aerossol, no tratamento tópico de amigdalite, concluíram que a benzidamina produziu uma melhora mais rápida do quadro clínico, indicando ser um potente antiinflamatório de uso tópico, recomendando seu uso nas afecções orofaríngeas e em amigdalectomias.

A atividade antiinflamatória da benzidamina no tratamento da mucosite oral é citada por Scully et al., ( 2006)

A ação terapêutica do dicluconato de clorexidina e da benzidamina, na forma de colutório, foi testada por Samaranayake et al. (1988), no tratamento de pacientes com mucosites induzidas por radiação, incluindo 
suas ações sobre bactérias e fungos presentes nesses casos clínicos. Concluíram que são pequenas as diferenças de ação entre os dois fármacos.

Karavana et al, (2011) demonstraram a ação da benzidamina sobre rec uperação de lesões orais induzidas em animais. Quanto a ação antimicrobiana Fanaki \& El Nakeeb (1992) avaliaram a atividade antimicrobiana da benzidamina sobre bactérias e fungos, em concentrações de $1 \%, 0,5 \%$ e $0,15 \%$, em contato com a solução teste por 30 minutos, usando diferentes técnicas, concluíram que a benzidamina é um agente antimicrobiano com rápida atividade biocida.

Simard \& Landry (1994) usaram a benzidamina e outros fármacos inibidores da placa bacteriana dentária, na forma de colutório, em cirurgias periodontais. Atribuíram à benzidamina um efeito anestésico local e uma capacidade de inibir a formação de placa bacteriana.

David Herrera et al., (2005), verificaram uma ação inibidora da formação de placa dental com o uso de colutório de benzidamina. a $0.15 \%$ associada ao cloreto de cetilpiridinio a $0,05 \%$.

Cingi et al. (2011) demonstrou que a associação de antibióticos com benzidamina reduzia significantemente os sintomas de amigdalites por estreptococos.

\section{MATERIAIS E MÉTODOS}

Utilizou-se neste experimento cloridrato de benzidamina, do Laboratório Sigma do Brasil, lote 28F1012, série b-5524 . $\mathrm{O}$ cloridrato de benzidamina foi diluído em água destilada estéril e as diluições foram mantidas em geladeira durante todo o experimento.

Na técnica dos poços utilizou-se sete soluções de benzidamina com concentrações que variaram de $1,56 \mathrm{mg} / \mathrm{mL}$ a $100,0 \mathrm{mg} / \mathrm{mL}$.

Para a técnica dos tubos, as concentrações das soluções variaram de 0,09 $\mathrm{mg} / \mathrm{mL}$ a $50 \mathrm{mg} / \mathrm{mL}$ de benzidamina.

As amostras microbianas (bactérias e fungos), usadas neste experimento, foram oriundas da ATCC e mantidas no Laboratório de Microbiologia da Universidade Federal de Alfenas-UNIFAL-MG , a seguir: Bacillus subtilis ATCC 6633, Candida albicans ATCC 10231, Enterococcus faecalis ATCC 19433 , Escherichia coli ATCC 8739, Proteus vulgaris ATCC 13315, Pseudomonas aeruginosa ATCC 9027, Salmonella typhimurium ATCC 14028, Serratia marcescens ATCC 8100 e Staphylococcus aureus ATCC 6538

Os testes de atividade antimicrobiana foram realizados por dois métodos, ou seja, teste de difusão em ágar e teste de diluição em tubo. No teste de difusão em ágar utilizou-se a técnica do poço, nos quais foram colocadas concentrações diferentes da benzidamina, no 
poço feito com tubo de metal no meio de cultura em placas de Petri, previamente inoculadas com microrganismos.

Foram preparadas soluções de benzidamina em concentrações decrescentes, ou seja, a 100,00 mg/mL, 50,00 mg/mL, $25,00 \mathrm{mg} / \mathrm{ml}, \quad 12,50 \mathrm{mg} / \mathrm{mL}, \quad 6,25 \mathrm{mg} / \mathrm{mL}$, $3,12 \mathrm{mg} / \mathrm{ml}$ e $1,56 \mathrm{mg} / \mathrm{ml}$. As soluções preparadas foram colocadas nos poços num volume de $28 \mu \mathrm{L}$. Após a secagem do liquido nos poços, as placas foram incubadas na posição invertida a $37^{\circ} \mathrm{C}$ por 24 horas. Após o tempo de incubação, foram feitas as leituras dos diâmetros dos halos de inibição do crescimento microbiano, medidos em milímetros, com auxilio de um paquímetro.

$\mathrm{Na}$ técnica da diluição em tubo foi avaliada também a concentração inibitória mínima (CIM) e a concentração bactericida/fungicida mínima (CBFM) da benzidamina, (Trupp 1986; Amsterdam 1991 e Jones 1985). Foram preparadas soluções de benzidamina em concentrações decrescentes, diluídas em Caldo Mueller Hinton ou em Caldo Sabouraud. Numa série de 11 tubos, foram colocados, respectivamente, $1 \mathrm{~mL}$ de Caldo Mueller Hinton ou Caldo Sabouraud contendo $100,00 \mathrm{mg} / \mathrm{mL}, 50,00 \mathrm{mg} / \mathrm{mL}, 25,00$ $\mathrm{mg} / \mathrm{mL}, 12,50 \mathrm{mg} / \mathrm{mL}, 6,25 \mathrm{mg} / \mathrm{mL}, 3,12$ $\mathrm{mg} / \mathrm{mL}, \quad 1,56 \mathrm{mg} / \mathrm{mL}, \quad 0,78 \mathrm{mg} / \mathrm{mL}, 0,39$ $\mathrm{mg} / \mathrm{mL}$ e $0,19 \mathrm{mg} / \mathrm{mL}$ de benzidamina. No tubo 11 , não foi adicionado a benzidamina, servindo como controle do crescimento microbiano.
Foi preparada uma suspensão microbiana e inoculada nos respectivos tubos contendo concentrações decrescentes de benzidamina. Os tubos inoculados foram levados á estufa a $37^{\circ} \mathrm{C}$ por 48 horas. Após a incubação foi avaliado crescimento microbiano pela presença de turvação do meio de cultura. Neste caso, determinou-se a concentração inibitória mínima (CIM), ou seja, a menor concentração de benzidamina capaz de inibir o crescimento microbiano. Para avaliar a concentração bactericida ou fungicida mínima da benzidamina(CBFM), cada tubo foi inoculado em Ágar Mueller Hinton ou Ágar Sabouraud e após incubação, a $37^{\circ} \mathrm{C}$ por 48 horas, foi realizada a leitura para a verificação da presença ou ausência do crescimento microbiano ou seja propriedade bactericida ou fungicida da droga.

\section{RESULTADOS}

$\mathrm{Na}$ determinação da concentração inibitória mínima da benzidamina pela técnica de difusão em Agar encontramos os seguintes resultados: nas concentrações de 100,00 $\mathrm{mg} / \mathrm{mL}, 50,00 \mathrm{mg} / \mathrm{ml}$ e $25,00 \mathrm{mg} / \mathrm{ml}$, todos os microrganismos testados, com exceção de Pseudomonas aeruginosa, apresentaram inibição do seu crescimento. Os maiores halos de inibição foram observados em Escherichia coli, Bacillus subtillis, Proteus mirabilis e Staphylococcus aureus. Os dados acima descritos encontram-se na tabela $01 \mathrm{e}$ 
representam a média aritmética de cinco experimentos.

Tabela 01 - Determinação da concentração inibitória mínima (CIM) da benzidamina pela técnica de difusão em Ágar

\begin{tabular}{l|ccccccc}
\hline $\begin{array}{c}\text { Concentração da } \\
\text { Benzidamina } \\
\text { (mg/mL) }\end{array}$ & & & & & & & \\
$\begin{array}{l}\text { Microrganismo/ } \\
\begin{array}{l}\text { Halos de inibição } \\
\text { em milímetros }\end{array}\end{array}$ & 100.00 & 50,00 & 25,00 & 12,50 & 6,25 & 3,12 & 1,56 \\
\hline & & & & & & & \\
Bacillus subtillis & 20,0 & 15,0 & 11,2 & 6,8 & 0,0 & 0,0 & 0,0 \\
Candida albicans & 13,2 & 10,0 & 6,2 & 0,0 & 0,0 & 0,0 & 0,0 \\
Enterococcus faecalis & 15,2 & 11,0 & 7,8 & 0,0 & 0,0 & 0,0 & 0,0 \\
Escherichia coli & 21,0 & 15,8 & 10,8 & 4,2 & 0,0 & 0,0 & 0,0 \\
Proteus mirabilis & 20,8 & 12,8 & 8,8 & 0,0 & 0,0 & 0,0 & 0,0 \\
Pseudomonas aeruginosa & 10,8 & 6,2 & 0,0 & 0,0 & 0,0 & 0,0 & 0,0 \\
Salmonella typhimurium & 13,4 & 9,2 & 7,0 & 0,0 & 0,0 & 0,0 & 0,0 \\
Serratia marcescens & 16,0 & 10,6 & 8,0 & 0,0 & 0,0 & 0,0 & 0,0 \\
Staphylococcus aureus & 18,0 & 14,6 & 11,0 & 4,0 & 0,0 & 0,0 & 0,0 \\
\hline
\end{tabular}

$\mathrm{Na}$ determinação da concentração

inibitória mínima (CIM) e concentração

bactericida/ fungicida mínima (CBFM) pela

técnica de diluição em tubos verificamos que

Escherichia coli mostrou-se sensível à ação

bactericida e bacteriostática da benzidamina a

0,39 mg/mL. Staphylococcus aureus,

Serratia marcescens, Proteus mirabilis $e$

Salmonella typhimurium, foram inibidos por

todas as concentrações testadas e não

apresentaram crescimento quando submetidos

a sub-cultivo, para determinação da apresentaram uma sensibilidade à ação bactericida da benzidamina a concentração de 0,09 mg/mL. Bacillus subitillis teve seu crescimento inibido por toda as concentrações de cloridrato de benzidamina, porém, nenhuma destas concentrações mostrou-se eficaz como bactericida.

\section{Enterococcus faecalis e Candida} albicans, apresentaram uma sensibilidade semelhante à ação bactericida/fungicida e bacteriostática / fungistática da benzidamina, até a concentração de $0,19 \mathrm{mg} / \mathrm{mL}$. concentração bactericida mínima, ou seja, 
A benzidamina na concentração de 0,39 $\mathrm{mg} / \mathrm{mL}$, mostrou-se bacteriostática e a 6,25 $\mathrm{mg} / \mathrm{mL}$, como bactericida para Pseudomonas aeruginosa. Os dados acima se encontram na tabela 02 e representam a média de três experimentos.

\section{DISCUSSÃO}

Vários estudos e relatos clínicos existem a respeito da atividade antiinflamatória e anestésica tópica da benzidamina, desde sua síntese em 1964 por Pallazzo. A sua atividade antimicrobiana, apesar de sugerida por alguns autores ainda necessitava ser ratificada em virtude dos trabalhos anteriores não serem totalmente conclusivos, o que inspirou este trabalho. $\mathrm{Na}$ literatura encontram-se pouquíssimos trabalhos de pesquisa comprovando sua atividade antimicrobiana mas sem dados efetivos que realmente possa colaborar na elucidação desta questão.

Cervera \& Uribe (1966) relatam uma ação antimicrobiana com concentrações elevadas de benzidamina, usando a técnica do poço.

Por esta mesma técnica do poço, Silvestrini et al. (1966) testaram e compararam a atividade da benzidamina, em relação à outros antimicrobianos, inclusive sobre a Escherichia coli, bactéria testada neste trabalho, porém, sem relatos dos valores das concentrações de benzidamina utilizadas.

Fanaki \& El Nakeeb (1992 ) expuseram bactérias e fungos à concentrações de $0,5,1,0$ e $15,0 \%$ de benzidamina, por 30 minutos, determinando inclusive a concentração inibitória mínima (CIM) e concentração bactericida/fungicida mínima (CBFM), sobre bactérias e fungos testados neste experimento. Amostras de Escherichia coli , mostraram-se sensíveis à uma CIM de $0,5 \%$ e CBM de $1,0 \%$. Neste experimento encontramos um valor de CIM e CBM de $0,39 \mathrm{mg} / \%$. Os resultados demonstraram que a Pseudomonas aeruginosa mostrou-se sensível à concentração de 12,5mg/mL (CIM e CBM ) e, segundo Fanaki \& El Nakeeb (1992), a CIM foi de 0,5\% e CBM de de 1,0 \%. Os Staphylococcus aureus, mostraram-se 
sensíveis a concentração de $0,09 \mathrm{mg} / \mathrm{mL}$, tanto na CIM , quanto na CBM. Segundo os autores a CIM encontrada foi de $1,0 \%$ e a CBM, na concentração de 2,0 \%. As amostras de Candida albicans testadas mostraram-se sensíveis a concentração de 0,19 mg/mL (CIM e CBM ) e, segundo Fanaki \& El Nakeeb (1992) , CIM na concentração 0,5 \% e CBM na concentração de $1,0 \mathrm{mg} / \mathrm{mL}$.

Estes dados mostraram, como os resultados obtidos pela técnica do poço, que as CIM são bem maiores daquelas encontradas na técnica de diluição em tubo. Em trabalho mais recente, Fanaki \& El Nakeeb (1996), novamente testaram a atividade antibacteriana e antifúngica da benzidamina, isolada e associada a outros antimicrobianos em bactérias resistentes a antibiótico, concluindo que a benzidamina exerceu uma atividade sinérgica quando associada aos antimicrobianos utilizados no experimento.

$$
\text { Chasseau \& Catanesi (1985) }
$$

demonstraram que o uso da benzidamina, na forma de soluções para uso ginecológico a
$140 \mathrm{mg} / \mathrm{ml}$, proporciona uma concentração plasmática de $0,02 \mu \mathrm{g} / \mathrm{ml}$ e, pela via oral, $100 \mathrm{mg}$ fornece uma concentração plasmática de $0,8 \mu \mathrm{g} / \mathrm{ml}$.

Portanto, baseado nessas afirmações, os comprimidos de $50 \mathrm{mg}$ de benzidamina disponíveis no comércio, proporcionam uma concentração plasmática de $0,4 \mu \mathrm{g} / \mathrm{ml}$, concentração distante da menor concentração com atividade antimicrobiana obtida, in vitro, neste experimento que, pela técnica dos tubos, foi de $0,09 \mathrm{mg} / \mathrm{ml}$, ou seja, valor 225 vezes maior que a concentração proporcionada pelos comprimidos. Essa é uma dosagem seguramente tóxica, portanto, inviável para ser administrada pois segundo Silvestrini (1966), a dosagem terapêutica da benzidamina em humanos, por via oral, deve ser em comprimidos de $50 \mathrm{mg}, 3$ a 4 vezes ao dia.

$$
\text { Pelos resultados obtidos neste }
$$
trabalho, a menor concentração de benzidamina, com atividade antimicrobiana, foi de $0,09 \mathrm{mg} / \mathrm{ml}$, e a concentração média, com efeito sobre os microrganismos testados, 
foi $0,25 \mathrm{mg} / \mathrm{ml}$. Isto indica que a benzidamina para ter atividade antimicrobiana deve ser usada somente para uso tópico pois as concentrações destas soluções possuem até $1 \mathrm{~g}$ $\%$, ou seja, concentração com atividade antimicrobiana conforme nossos resultados.

A testada ou seja C. albicans apresentou sensibilidade semelhante as encontradas nas bactérias.

Uma maior resistência encontrada nas bactérias do gênero Bacillus pode ser explicada por se tratar de bactéria esporulada.

Em trabalho mais recente Pina-Vaz et al., (2000) determinaram a CIM da benzidamina sobre amostras de C. albicans utilizando sondas fluorescentes e encontraram um valor entre 12,5 a $50 \mathrm{mg} / \mathrm{mL}$ valores estes próximos aos encontrados neste trabalho utilizando a técnica de difusão em ágar.

\section{CONCLUSÃO}

Os resultados obtidos neste experimento nos permitem concluir que:

1- A benzidamina exerce efeitos antibacterianos e antifúngicos em altas concentrações.
2- Nas concentrações efetivas com ação antimicrobiana ela deve ser indicada somente para uso tópico como pastilha, colutório, géis, sendo inviável a indicação para uso sistêmico, o que certamente levará à uma ação tóxica no organismo.

3- Os resultados obtidos pela técnica do poço (difusão em ágar) foram semelhantes aos obtidos pela técnica de diluição em tubos, porém com CIM bem menores.

4- Pela técnica dos tubos, determinou-se as concentrações mais precisas na obtenção da CIM e CBM da benzidamina porém com a técnica do poço somente podemos determinar a CIM.

\section{REFERÊNCIAS}

1. AMSTERDAM, D. The suceptibility testing of antimicrobials in líquid médic. In: ANTIBIOTICS in laboratory medicine.Baltimore: The Willians \& Wilkins, p.53-105, 1991.

2. BALERCIA, L. Benzidamina pasta en el tratamiento local de algunas manifestaciones odontoestomatológicas. Revista ADM, México, v. 23, n. 5, p. 44-48, Sep./Oct.,1976.

3. CERVERA, A.C. ; URIBE, F.G. Química, farmacologia y toxicologia de la benzidamina. Medicamenta, Madrid, v. 424, t. 24, p. 157-162. 1966.

4. CHASSEAUD, L.F.;CATANESE, B. Pharmacotinetics of benzydamine. Int. J. 
Tissue React, v. 7, n. 3, p. 195-204, 1985.

5. CINGI C, SONGU M, URAL A, ERDOGMUS N, YILDIRIM M, CAKLI

H, BAL C. Effect of chlorhexidine gluconate and benzydamine hydrochloride mouth spray on clinical signs and quality of life of patients with streptococcal tonsillopharyngitis: multicentre, prospective, randomised, double-blinded, placebo-controlled study. J Laryngol Otol. Feb 11:1-6. 2011

6. DAVID HERRERA, SAGRARIO SANTOS, JORGE FERRÚS, GERMÁN BARBIERI, LEONARDO TROMBELLI AND MARIANO SANZ, Efficacy of a $0.15 \%$ benzydamine hydrochloride and $0.05 \%$ cetylpyridinium chloride mouth rinse on 4-day plaque formation, Journal Of Clinical Periodontology , 32 Page 595, June 2005.

7. DEF, Dicionário de Especialidades Farmacêuticas, , Rio de Janeiro ,Editora de Publicações Científicas Ltda,2002.

8. DE GREGÓRIO, M. Some clinical data on benzydamine. Excerpta Medica

Internacional, Milan,p.429,1964.

9. FANAKI, N.H.;EL-NAKEEB, M. A. Antimicrobial activity of benzydamine, a non-steroid anti-inflammatory agent.

Journal of Chemotherapy, Firenze, v. 4, n. 6, p. 347-352, Dec. 1992.

10. FANAKI, N.H.;EL-NAKEEB, M.A. Antibacterial activity of benzydamine and antiobiotic-benzydamine combinations against multifold resistant clinical isolates. Drug Res., Aulendori, v. 46, n. 1, p. 320-323, Mar. 1996.

11. GANANÇA, M.M. et al. Estudo comparativo entre cloridrato de benzidamina versus hexamidina associada ao cloridrato de tetracaína no tratamento tópico das amigdalites. Rev. Bras. Med., Rio de Janeiro, v.45, n.3, p.66, mar. 1988.
12. JONES, R. N. et al. Suceptibility tests: microdiluition and macrodiluition broth procedures. Whashington:American Society for Microbiology, 1985. p.972977.

13. KARAVANA HIZARCIOĞLU SY, SEZER B, GÜNERI P, VERAL A, BOYACIOĞLU H, ERTAN G, EPSTEIN JB. Efficacy of topical benzydamine hydrochloride gel on oral mucosal ulcers: an in vivo animal study, Int J Oral Maxillofac Surg. Sep;40(9):973-8. 2011

14. KIM, J.H.; CHU, F.C.; LAKSHMI, V.; HOUDE, R. 1986. Benzydamine HCl, a new agent for the treatment of radiation mucositis of the oropharynx. Am. J. Clin. Oncol. 9:132-134

15. KOROLKOVAS,Andrejus. Química farmacêutica. Rio de Janeiro: Guanabara Dois,1982. p.210.

16. MARCHIORI, C. Valutazione clinica delle attività antiflogistica ed analgesica della benzidamina collutorio. Il Valsalva, v.48, n. 4, p.1-11, 1972.

17. PINA-VAZ C. et al. Antifungal activity of local anesthetics against Candida species. Infect.Dis.Gynecol; V.8, N.3-4,P.124-37, 2000.

18. SCULLY C, SONIS S, DIZ PD, . Oral mucositis. Oral Dis. May;12(3):229-41. 2006

19. SAMARANAYAKE, L.P. et al. The effect of chlohexidine and benzydamine monthwashes on mucositis induced by therapeutic irradiation. Clinical

Radiology, Bristol, v.39, n.3, p.291-294, May, 1988.

20. SILVESTRINI, B. et al. Toxicoloy of benzydamine. Toxicology and Aplied Pharmacology, San Diego, v.10, n.1, p.149-159, Jan. 1966.

21. SIMARD, F. and LANDRY, R.G. Mouthrinses as an antibacterial adjunct in periodontal treatment. Jour. Lan. Dent. 
Assoc., Otawa, v.60, n.10, p.906-907. 910-911, Oct., 1994.

22. THE MERCK index; an encyclopedia of chemicals, drugs, and biologicals. 10th. ed. Rahway :Merck \&Co,. p.151-160. 1983.

23. TRUPP, L.D. Susceptibility testing of antibiotics in liquid media. In: Antibotics in Laboratory Medicine. Baltimore : The william \& Wilkins, 1986. P. 93 -110.

24. WHITESIDE, M.W. A controlled study of benzydamine oral rinse (Difflam) in general practice. 
Tabela 02 - Determinação da concentração inibitória mínima (CIM) e da concentração bactericida/fungicida mínima (CBFM) da benzidamina pela técnica da diluição em tubo

\begin{tabular}{|c|c|c|c|c|c|c|c|c|c|c|c|}
\hline $\begin{array}{l}\text { Concentração da } \\
\text { Benzidamina }\end{array}$ & | $50 \mathrm{mg} / \mathrm{mL}$ & $25 \mathrm{mg} / \mathrm{mL}$ & $12,5 \mathrm{~m} / \mathrm{mL}$ & $6,25 \mathrm{mg} / \mathrm{mL}$ & $3,125 \mathrm{mg} / \mathrm{mL}$ & $1,56 \mathrm{mg} / \mathrm{mL}$ & $0,78 \mathrm{mg} / \mathrm{mL}$ & $0,39 \mathrm{mg} / \mathrm{mL}$ & $0,19 \mathrm{mg} / \mathrm{mL}$ & $0,095 \mathrm{mg} / \mathrm{mL}$ & $\begin{array}{l}\text { Controle } \\
\text { positivo }\end{array}$ \\
\hline Bacillus subtilis & & & & & & & & & & & \\
\hline CIM & - & - & - & - & - & - & - & - & - & - & + \\
\hline $\begin{array}{r}C B M \\
\text { C. albicans }\end{array}$ & + & + & + & + & + & + & + & + & + & + & + \\
\hline CIM & - & - & - & - & - & - & - & - & - & + & + \\
\hline $\begin{array}{r}\text { CBM } \\
\text { E. coli }\end{array}$ & - & - & - & - & - & - & - & - & - & + & + \\
\hline CIM & - & - & - & - & - & - & - & - & + & + & + \\
\hline $\begin{array}{r}C B M \\
\text { E. faecalis }\end{array}$ & - & - & - & - & - & - & - & - & + & + & + \\
\hline$C I M$ & - & - & - & - & - & - & - & - & - & - & + \\
\hline $\begin{array}{r}C B M \\
\text { P. aeruginosa }\end{array}$ & - & - & - & - & - & - & - & - & - & + & + \\
\hline$C I M$ & - & - & - & - & - & - & - & + & + & + & + \\
\hline$C B M$ & - & - & - & + & + & + & + & + & + & + & + \\
\hline $\begin{array}{r}\text { Proteus mirabilis } \\
\text { CIM }\end{array}$ & - & - & - & - & - & - & - & - & - & & 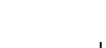 \\
\hline $\begin{array}{r}C B M \\
\text { S.aureus }\end{array}$ & - & - & - & - & - & - & - & - & - & - & + \\
\hline CIM & - & - & - & - & - & - & - & - & - & - & + \\
\hline$C B M$ & - & - & - & - & - & - & - & - & - & - & + \\
\hline $\begin{array}{r}\text { S. marcescens } \\
\text { CIM }\end{array}$ & - & - & - & - & - & - & - & - & - & - & + \\
\hline S. typhimurium & - & - & - & - & - & - & - & - & - & - & + \\
\hline$C I M$ & - & - & - & - & - & - & - & - & - & - & + \\
\hline$C B M$ & - & - & - & - & - & - & - & - & - & - & + \\
\hline
\end{tabular}

CIM = Concentração Inibitória Mínima ; CBFM= Concentração Bactericida/Fungicida Mínima;

(+) presença de crescimento microbiano; (-) ausência de crescimento microbiano. 